\title{
On Employment Opportunities for Albanian Young People in Rural Areas through Sustainable Development of Traditional Farm
}

\author{
Enida Kume \\ PhD student, Faculty of Social Science, \\ Public Tirana University, Albania
}

Doi:10.5901/ajis.2013.v2n3p83

\begin{abstract}
Youth employment is a global challenge. Its complexity is particularly large in the case of young people who live in rural areas. The growth of the agricultural economy in a free market area, tending to an intensification system, reduces work opportunities for young people living in rural areas. Finding a solution that reconciles these two processes in an optimal point is becoming a necessity. The promotion and development of traditional farms is one of the best solutions. Traditional farms that enables this achievement of the added value for all manufacturing as potential sources of biological diversity in animals and plants, nature, environment, water, forests, traditions, ethno culture, etc. These farms generate opportunities for the development of nonagricultural economic activities, which are a real possibility for a constant increase in the rural youth employment level. The Territorial Treaties for Youth Employment is one the most effective tools for rural youth employment, but they must also address the possibilities for the promotion of traditional farms with all the necessary issues. Thus, technical and professional training for young people to cope with the farm work, subsidies, incentives for growth and management of the farms, etc. will be supported.
\end{abstract}

Keywords: Employment, youth, rural areas, traditional farm

\section{Introduction}

The 2010-2013, Action Plan for Youth Employment considers, employment of youth living in rural areas, as one of the most complex issues. The Albanian Strategy and National Plan of Action for Sustainable Rural Development considers one of its main priorities the sustainable and long term solution for this issue. The complexity of the problems to be solved in order to increase employment opportunities for young people in rural areas is present not only in developing countries. Developed countries also face these problems. EU has spent lots of energy on finding an optimal solution. The program "Support for young farmers" is one of the main programs of the EU (www.ceryc.eu; Aggelopoulos and Arabatzis. 2010). It addresses the needs of young people in rural areas. The objective of this program is to support and create proper conditions for young people in order to face the challenges of their work and life in rural areas by creating new job opportunities through support, promotion and development of agricultural production activities and non-agricultural, services, trade, etc. This program dedicates a special place for the support of youth initiatives, to establish traditional family farms, which enable increased competitiveness of local agricultural and livestock products and also tourism and agro-tourism development.

The object of this study is to address issues related to Albanian youth employment in rural areas. It is focused on issues related to the opinions, perceptions and expectations of young people who live in rural areas and the strategic priorities set out in youth employment Strategy. The aim of this study is to assess their compliance level with the objectives set out in the Territorial Pacts for Youth Employment and Rural Development Strategy. To achieve this goal, the research is focused on addressing issues related to the sustainable development of traditional farm, as one of the optimal opportunities for increasing capacity in the labor market, for young people living in rural areas.

\section{Study Methodology}

The study methodology was built in accordance with the principles of comparative analysis.

The analysis was focused on the comparison of supply and road solutions proposed by the Strategy and Action Plan for youth employment and sustainable development of rural areas and the perceptions and opinions of young people toward opportunities, life and employment prospects in rural areas. The Analysis was carried out by referring to the 
method and principles published on "Study on Employment, Growth and Innovation in Rural Areas (Rural development policy on women and young people. ECORYS Nederland BV, 2010)".

\subsection{Hypotheses}

The working hypothesis on which was based the performance of this study were:

1. The decision of young people to work in rural areas is affected by the perception and the level of information about the effects of the programs for economic and social development of these areas, on their living conditions;

2. Sustainable development of traditional farm has a big impact on this decision making process.

\subsection{Objectives}

The research conducted as part of the identification and study of issues related to the labor market complexity of young people in rural areas had as main objectives:

i. To assess the knowledge, opinions, perceptions and expectations of young people's for policies, strategies and action plans related to youth employment in rural areas.

ii. To evaluate youth approach to traditional farm employment and self-employment opportunities

\subsection{Applied Methodologies}

In order to evaluate the relationship between youth and opportunities, routes and instruments provided by employment policies in rural areas, the interviews were focused on issues related to: (i) youth level of information about policies of economic and social development of rural areas; (ii) youth opinion about real opportunities for employment and selfemployment; (iii) youth support and their expectations for the initiatives of traditional farm development.

The questionnaire was drafted taking into account the methodology that addresses issues of youth employment in rural areas (Hope For Young People in Rural Areas. IFAD\&ILO,2011)

\subsection{Sample description}

186 young people living in hilly and mountainous regions in Korca district (municipality Liqenas), Dibra region (Doda Castle municipalities), Lezha district (municipality Kallmet) and Gjirokastra district (municipality Picar) Vlore region (municipalities Armen) were interviewed. The random selection criterion was used to form the sample. The formed sample was composed by $48.9 \%$ girls and $51.1 \%$ boys. Young people aged $20-30$ years accounted for $44.6 \%$ of the sample and aged $26-30$ years for about $55.4 \%$.

\section{Results and Discussions}

\subsection{Youth employment - a challenge for sustainable rural development}

Employment in the agricultural sector in Albania has reached a peak in 2002, with $71.2 \%$ of total employment, and then it went down to $43.4 \%$ in 2008. In 2009, the employment in this sector marked an increase of $14.3 \%$, compared with 2008 , indicating in this way, the beginning of an upward trend in the volume of economic activities in the agricultural sector (Albania: Youth Employment Action Plan 2010-2013. www.un.org.al)

According to the ILO, in the period 1996-2008 new job offerings in Albania has been inadequate, especially in the agricultural sector. Meanwhile, since the population in rural areas is relatively new, about $53 \%$ are under 55 years old and the other $24 \%$ under 65 years old, the employment requirements for this sector are mainly dominated by young workers with low education.

The Inter-sectorial Strategy for Rural Development (2007-2013) contains the priorities for sustainable rural development. These priorities aim at strengthening the multifunctional role of the Albanian agriculture. The focus is on the agriculture needs and agro-industry restructuring, to enhance competitiveness of the entire agricultural sector and the agro-food chain. The strategy emphasizes the important achievement of objectives related to socio-economic growth in rural areas through the introduction of new methods which will seek to generate increased employment opportunities in 
all agricultural activities. The Strategy define as strategic priorities: (i) sustainable growth of farm income, (ii) management of natural resources including forests, pastures and water, and (ii) the creation of new employment opportunities and better quality life through diversification and improvement of rural infrastructure.

Trends and developments of recent years highlight the potential for the realization of a modern and competitive agricultural sector, only if it is provided by an appropriate political climate that will serve as incentive for private targeted investments. However, while other sectors continue to grow, the relative contribution of agriculture to GDP tends to decrease. Consequently, the percentage of workers in agriculture will decrease. This expected situation, demands for solutions that will reach out to harmonize, in the best way possible, policies and actions in meeting the objectives of the Strategy for Sustainable Rural Development and the Sectorial Employment Strategy.

Currently, the sustainable rural development is considered as one of the global challenges of the century. EU countries have activated enormous energy to successfully meet this challenge. In multilateral efforts planned to be carried out, EU countries have placed great attention to the creation of necessary socio-economic conditions in order to enable higher employment of young people in rural areas. "Support for young farmers" is one of the main programs of the EU, which addresses the needs of young people in rural areas (Hope For Young People in Rural Areas. \& IFAD ILO, 2011).

Sustainable rural development in Albania, along with the objectives of raising up life standards of the population, aims also to encourage and support the growth of labor market capacities in these areas. This has conditioned the implementation and development of programs which enable a sustainable management of all renewable natural resources, protection of the environment, preservation of the cultural landscape of rural identity, preservation and administration of forests, water and biological diversity, promoting support the production of alternative economic activities etc..

Youth Employment Territorial Pacts (Zampini, 2012) is an opportunity which seeks an optimal solutions that can enable economic and social development of rural areas by encouraging and supporting young people to live and work in these areas. Development of traditional farm and youth capacities, for managing their support in order to revival the tradition in the production and processing of local food, the promotion of initiatives which aim at promoting the development of non-agricultural activities, agro-tourism, etc.., as part of the National Action Plan for Rural Development must be treated at the same time, as a challenge of the National Action Plan for youth Employment. In this way the problems and challenges of youth employment in rural areas can be treated in accordance with the EU and developed countries standards (Study on Employment, Growth and Innovation in Rural Areas. ECORYS Nederland BV, 2010).

\subsection{Information, assessment and expectations of young people, toward employment and sustainable rural development policies.}

Informing young people about what is provided by the public policy is a serious moment with significant effect on their decision making and behavior toward future employment / self-employment. The evaluation of these policies and their expectations are essential factors in the formation of this behavior. The identification of needs and priorities of young people, to develop their capacities in order to fulfill the labor market demands and trends of economic and social development of rural areas, is a key moment that conditions the success of youth employment policies in rural areas.

Among the young people interviewed about $36.0 \%$ answered that they were pro the immigration alternative. Among them, about $19.4 \%$ were girls and $80.6 \%$ boys. About $49.4 \%$ of young people aged $20-25$ years were pro this alternative, while among young people aged $26-30$ years only about $24.3 \%$ had intentions to migrate to urban areas

About $68.8 \%$ of the young people interviewed was working on the family farm, about $21.5 \%$ were employed in nonagricultural activities away their residence and $9.6 \%$ in non-agricultural activities in their community.

Referring to demographic phenomena occurring in the last two decades, and whose characteristic was the high percentage of population migration from rural to urban areas and in particular the emigration of young people inside and abroad the country, young people who live in rural areas are currently developing a different attitude. Meanwhile, as the self-employment in farm agricultural work is a the most occurred one, the promotion, support and development of opportunities, alternative activities in non-agricultural production and businesses for youth in rural areas is the need of the time. Territorial Employment Pacts is one of the ways to achieve this goal (Zampini, 2012).

About $61.3 \%$ of young people interviewed said they had no information about policies and programs that have as their objective to support employment, training and awareness of young people to avoid informal employment, grants, possible ways of support and financial instruments to realize their self-employment initiatives. This level of information changes from one region to another (Fig.No.1). In general, young people aged 25-30 years and boys were more informed (Fig.No.2). 


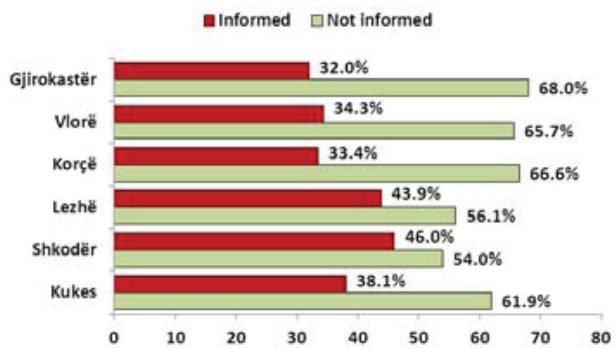

Fig.1: The level of information of the youth by regions

In districts where Territorial Employment Pacts are applicable, as Shkodra, Lezha and Kukes, the level of information is higher. Differences in the level of information among young people of different ages and genders shows that, in general, schemes used for their information have not been effective (Zampini, 2012).

The level of assessment of the effects of public policies and programs on the decision of young people to work and live in rural areas is low. About $67.4 \%$ of boys and about $80.2 \%$ of girls said that their decision does not depend on these policies. Also, low is the expectation of young people to the products of public policies and programs. About $74.5 \%$ of respondents said they do not expect and do not believe that they will be supported in their employment initiatives. About $71.5 \%$ of boys and about $76.3 \%$ of girls associate the success of their initiatives for employment / self-employment with the personal efforts and support from family.

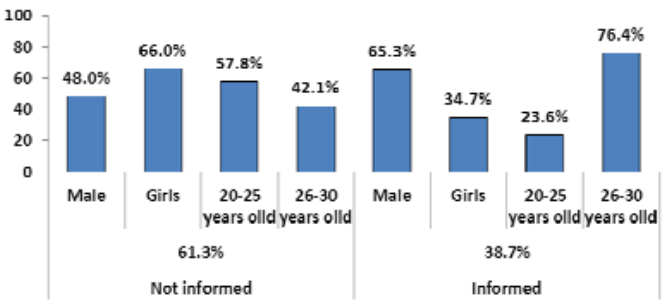

Fig.2: The level of information among young people depending on gender and age

Among young people who does not consider an alternative moving to urban areas, about $57.5 \%$ of boys and $70.3 \%$ of girls, think that most probably they will be employed in the family farm.

These results suggest that the policies and programs for youth employment in rural areas have not managed to attract the attention of young people youth expectations shows that the effects and real products of these public policies and programs are far away from their declared objectives. Consequently, it is necessary to reflect changes that can get them closer to the interest of young people. They are required to be as concrete as possible and create more opportunities for youth access. It is necessary to avoid sterilized schematization.

They should be consistent with young people interests, psycho-social predisposition of various social groups, professional training of young people, tradition and culture in rural areas, social and economic development of the area, potential opportunities for development of agricultural and non-agricultural alternative activities, etc. In this context, supporting young people to develop traditional farm, especially in hilly and mountainous regions of the country, is one of the ways that the European experience considers as among the most successful.

\subsection{Traditional farm development - an alternative option for youth employment.}

The implementations of activities that create greater employment opportunities for young people in rural areas, is associated with the creation of family enterprises, farms development, small non-agricultural businesses, services, agrotourism etc. These should be based mainly on the competitiveness advantages of the countryside. Among these advantages can be listed, environmental and historical and cultural traditions assets, handicrafts and traditional food, climate, geography, diversity and beauty of landscapes, forests etc. Traditional Farms is one of the most effective alternatives for the optimal use of these advantages (Nation, 2005; Kazimirski, 1998). In particular, such a farm can be developed very successfully in hilly and mountainous regions of the country. 
$28.3 \%$ of young people interviewed had as their objective the development of traditional farm, while about $34.4 \%$ intended to develop alternative production activities in existing farm. The idea to set up a traditional farm is much more common in boys, while girls tend, in their majority, to develop an alternative production activity such as growth of rabbits, birds of local races, etc. (Tab.No.3)

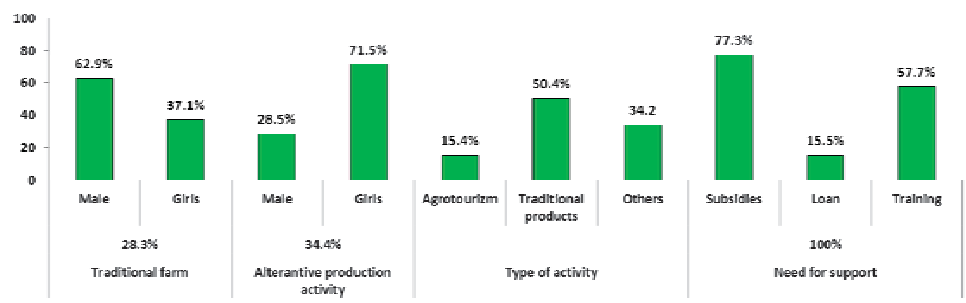

Fig.3: Opinions of youth about the issues related to production activities that want to be developed in family farm

Only about $15.4 \%$ of the respondents consider traditional farm as an opportunity for agro-tourism development, while about $50.4 \%$ aim through it to produce traditional food products, which are competitive products in the market. All of them expressed the need for financial support.

About $77.3 \%$ of them seek to rely on subsidies from public funds and only $15.5 \%$ consider getting a loan as financing option for building traditional farms or a farm alternative manufacturing activity. The need for training to develop professional capacity and farm management was expressed by $57.7 \%$ of the youth.

The above results show that young people in rural areas, in general, are not well informed about the advantages that traditional farms and / or development of an alternative manufacturing activity in the family farm is a real opportunity for self-employment. They are not informed and / or do not have much confidence in public financial institutions as potential partners in the implementation of their ideas and as the entity that will enable the production of goods for living in rural area.

\section{On Traditional Farm}

Traditional farm is the economic unit that can create real opportunities for traditional products, food and clothing Made in Albania and demonstrate the tradition and culture of ethno Albanians, who have lived for centuries in these regions. A traditional farm is a farm that breeds animals of local races, that invites anyone to touch, to feel and to be part of a working process based on the conditions and traditions followed by the inhabitants of these regions in centuries

Traditional farm is subject to multiple production potentials. It is the economic entity that offers variations in employment opportunities. Is the unit around which and with which structures can be built and programs for agro-tourism development can be implemented.

Traditional Farms is an entity which provides, in the most efficient manner, an added value for agricultural and livestock products. This farm offers all the necessary potential to produce local bio products. Traditional farm, with its products, is the best opportunity for Albanian farmers, to be part of regional and global market. Traditional Farms is the entity that enables the development of non-agricultural activities, agro-tourism etc. For these reasons, traditional farming is one of the important generating employment opportunities for young people in rural areas. To make this possible it is necessary to develop supportive policies and to plan the necessary interventions in infrastructure, roads, water supply and electricity. It is very important to develop an all-comprehensive legal base. The realization of a long-term program to educate the public for more awareness toward the natural values of the Albanian cultural heritage. Development of the vocational education system and training advisory service for young people, are among the factors that condition the success of any initiative that aims to increase the employment opportunities of young people in the village by involving them in non-agricultural activities, which can be developed based on the opportunities offered by traditional farming.

Such developments are part of the objectives set out in the Inter-Sectorial Rural Development Strategy, 20072013. To fulfill this objectives Albania has started the Farmers Subsidy System with good results. Currently, the government subsidizes part of the investments made in agriculture, orchards, fruit-growing, livestock and agro processing industry. Actually Albania is working on developing the capacity of the public advisory service, which offers training and assistance to farmers. Despite this, referring to the opinions and expectations of young people, it is necessary to support them on their work and life in rural areas by setting out concrete objectives and actions. Young people need support and subsidies for their initiatives, they need to further develop their professional capacities, in order to be educated. 
The Territorial Pacts for Youth Employment are the most important products of the "Youth Migration Program". The benefits gaining and risk mitigation of this program were implemented as a product of cooperation between the Albanian government and the ILO, IOM, UNDP and UNICEF (Zampini, 2012).

The analysis of the achievements to date of these Pacts reveals differences in the treatment of issues related to employment or informal employment of youth in urban and rural areas.

In most cases, youth employment in rural areas is considered as part of the possible solutions that can be achieved in the context of sustainable rural development of these areas. The most important contribution in this context is given by the implementation of grant schemes offered by the Albanian government.

These Pacts does not pay attention and do not provide for instruments that will encourage and enable youth employment in rural areas through the revitalization of traditional farms. Pacts do not refer to the traditional farm, as one of the most effective options for sustainable use of biodiversity, natural resources and environmental variety, tradition and ethno culture, the development of rural tourism and regional market access through traditional products. Consequently they have failed to exploit this opportunity, which will have significant effects on youth effective employment and on getting them back to live in rural areas.

Supporting youth initiatives for the development of traditional farm, encouraging them and creating the necessary conditions for the success of these initiatives, is one of the most effective ways for sustainable employment of young people in rural areas.

\section{Conclusions}

- Youth employment is a global challenge. Its complexity is particularly large in the case of young people who live in rural areas.

- Development of the agricultural economy in terms of free and open market economy, tending to increase the intensification level as a condition for sustainable rural development, reduces employment opportunities for youth in rural areas. A solution that can give an optimal compromise between these two processes is a necessity.

- Traditional Farms enables the development of non-agricultural economic activities.

- Its development is a real opportunity to increase the level of sustainable employment for young people.

- The Territorial Pacts for Youth Employment, as one of the effective tools for youth employment in rural areas, should address opportunities for the development of traditional farms by considering all the necessary issues, from the professional and technical education of youth in order to better face the challenges of this employment till subsidizing youth initiatives for building up and managing these farms.

\section{References}

Albania: Youth Employment Action Plan 2010-2013. www.un.org.al

Allan Nation. 2005. "How We Farmed: Traditional American Farming Techniques and What We Can Learn from Them" Wise Traditions in Food, Farming and the Healing Arts, Weston A. Price Foundation

Aggelopoulos, S., Arabatzis, G. 2010. European Union young farmers program: a Greek case study. NEW MEDIIN 2/2010 p. 50-55

Hope For Young People in Rural Areas. 2011 International Fund for Agricultural Development (IFAD) and the International Labour Office (ILO)

Legislation: Sectorial Employment Strategy 2007 - 2013. Ministry of Work, Social Affairs and Equal Opportunities, November, 2007

Legislation: Crosscutting Strategy for Rural Development, 2007-2013. Ministry of Agriculture, Food and Consumers Protection, Tirana, November. 2007 p.20-27

Legislation: Strategy for Agriculture and Rural Development (2007-2013). Ministry of Agriculture, Food and Consumers Protection, Tirana, November. 2007

Luc Kazimirski 1998."Traditional Agriculture". Biology 4806 . Special Topics.

Study on Employment, Growth and Innovation in Rural Areas - ANNEX - Rural development policy on women and young people. 2010 ECORYS Nederland BV

Support for young farmers in the European Union. 2009. Education and Culture DG. Europe for Citizens`Program, www.ceryc.eu.

Zampini, D. 2012. Local Employment Development: Albania's experience with territorial employment pacts and regional employment funds. AER Conference "Why are regions best positioned to tackle youth employment?" June, 26. Tirana, Albania. 